\title{
What makes a blockbuster video game? An empirical analysis of US video
}

\section{game sales}

\begin{abstract}
This study uses a unique dataset of individual video game titles to estimate the effect of an exhaustive set of observable characteristics on the likelihood of a video game becoming a blockbuster title. Due to the long-tailed distribution of the sales data, both OLS and logistic regression models are estimated. The results consistently show that blockbuster video games are more likely to be released by one of the major publishers for popular hardware platforms. Results also show that games of higher quality are significantly more likely to sell a greater number of units than those of a lower quality.
\end{abstract}

Keywords: Blockbuster; killer-app; triple-A; video games

Acknowledgements: I would like to thank James Tarbuck for his assistance in compiling the dataset used as part of the empirical analysis in this paper. 


\section{1: Introduction}

So-called or blockbuster or 'triple-A' titles are a well-known feature of entertainment industries. The blockbuster movie is a particularly familiar concept, with the second instalment of 'Harry Potter and the Deathly Hallows' setting a box office record by earning $\$ 169$ million in revenue during its opening weekend in July 2011 (The Economist, 2011). Other mainstream forms of entertainment, such as music and books, are also associated with a limited number of releases that generate disproportionately high sales and revenues. For example, the book 'Harry Potter and the Deathly Hallows' generated $\$ 220$ million revenue generated in the first twenty-four hours of release. A comparatively recent addition to these more familiar and mainstream forms of entertainment is video gaming. In the latter part of the previous decade, several major video gaming releases have raised the bar for conventional entertainment goods in terms of revenues earned. Since the launch of 'Halo 3' by Microsoft in 2007 and 'Grand Theft Auto IV' by Rockstar Games in 2008, the 'Call of Duty' series by Activision has produced a series of annual records for revenues over the course of a three year period. For example, in 2009, 'Call of Duty: Modern Warfare 2' sold 4.7 million copies in twenty-four hours in the UK and US, earning $\$ 310$ in revenue. In November 2010, 'Call of Duty: Black Ops' sold 5.6 million units in its first day and $\$ 650$ million revenue in its first five days. The title went on to earn \$1 billion in its first month of release.

More recently, 'Call of Duty: Modern Warfare 3'has eclipsed all of these records by selling 6.5 million units on the first day of release in November 2011, raising $\$ 400$ million in revenue in the UK and US (The Guardian, 2011). The game has gone on to generate $\$ 750$ million in revenue over the first five days of its release and $\$ 1$ billion in revenue within the first sixteen days. This narrowly overcame the previous entertainment record set in 2009 by the James Cameron film 'Avatar', which achieved \$1billion in revenue within the first seventeen days of release (Activision, 2011b). In addition, the launch of 'Modern Warfare 3' represented the best-selling game of all time at each of the top five U.S retailers and set a further record for having 3.3 million unique players online in a single day 
(Activision, 2011a). The success of these games is such that life-to-date sales for the Call of Duty franchise exceed those of popular franchises 'Star Wars' and 'Lord of the Rings' (Eurogamer, 2011).

Video game software is traditionally played on a range of different (and incompatible) hardware models, commonly known as consoles. These consoles can either be connected to a power outlet and a television set, or can take the form of a handheld/portable device that gamers charge and play outside of the home. Consoles are manufactured by the Japanese companies Nintendo and Sony, as well as the American company Microsoft whose consoles of the current hardware generation are the Wii, Playstation 3 (PS3) and Xbox 360 respectively. Additionally, both Nintendo and Sony have competing handheld platforms in the DS and PSP respectively. Figure 1 shows the cumulative North American sales of all of these consoles during the period analysed in this study (2004-2010), as sourced from the analysis site VGChartz (2011). It can clearly be seen that the Nintendo consoles have dominated other hardware platforms since 2007, with the DS and Wii selling just over fifty and just under forty million units respectively up to the end of 2010. The Microsoft Xbox 360 follows as the home console with the second largest installed user base in North America, with just under twenty-seven million units sold to date. The consoles with the lowest sales figures in this generation have been produced by Sony, with the handheld PSP selling just over twenty-one million units and the PS3 selling just over eighteen million units in North America up to the end of 2010.

[Figure 1 about here]

The business model of video game publishers is becoming increasingly geared towards achieving the goal of high sales volumes, with Aoyama \& Izushi (2003) demonstrating that software publishers face negligible marginal cost and high up-front development (fixed) costs. Scale economies therefore dictate that blockbuster titles will earn huge profits, whereas flops can generate financial disaster. Academic evidence increasingly points to video gaming becoming an industry where a handful of titles are increasingly sharing a majority of revenues (Coughlan, 2001). Shintaku \& Ikuine (1999) suggest that fourteen per centof titles generate over seventy per cent of industry sales. In the 
sample of video games titles analysed by Clements \& Ohashi (2004), it was acknowledged that the top five per cent of titles had been responsible for more than fifty per cent of software revenue, while Shankar \& Bayus (2003) claim that only ten per cent of games earn a profit and nearly half of all titles sell fewer than ten-thousand copies. In addition, the same study argues that a blockbuster title can return two to three hundred times the cost of production within a year and can also subsequently be exploited into franchised series, which helps to drive forward technological frontiers as a result of high consumer expectations with regard to subsequently released titles.

\section{2: Literature Review}

The literature on the phenomenon of the blockbuster has understandably tended to focus on Hollywood movies. Studies by De Vany \& Walls (1999), Prag \& Casavant (1994), Smith \& Smith (1986), Sochay (1994) and Wallace et al. (1993) have all investigated the success determinants of films. Collins et al. (2002) examine the UK film market, attempting to empirically estimate the influence of a variety of factors that contribute to a blockbuster. They emphasise the problems of using OLS regression where there is a heavily tailed distribution and instead advocate the use of a transformation of the dependent variable into binary form.

There is a relatively limited academic literature focusing on the factors that define blockbuster video game titles. One of the earliest mentions of gaming in this context was by Neuman (1991), where video games were described as a 'hits business'. Subsequent studies by Cringely (1996) and Williams (2003) looked into so-called 'killer-apps', which are so desirable as to induce consumers to go out and spend several hundred dollars on the hardware necessary just to be able to play them. Gallagher \& Park (2002) suggest that technological advances allow for better imagining of established franchises, often providing in-house killer apps. This conclusion is further supported by the work of Evans et al. (2005), who find that virtually all killer apps have been produced by console manufacturers themselves; the one exception being Sony's Playstation, which achieved major 
success in the absence of a killer app. Instead, Sony was able to attract a variety of software from a wider range of developers though the simplicity of their development tools.

More recently, Binken \& Stremersch (2008) distinguish between the different terminologies used to define a successful game. They suggest that high quality games are 'superstars', while 'hits' or 'blockbusters' refer to titles with high sales volumes and 'killer app' refers to software that allows one hardware platform to dominate another. This study also finds evidence of a positive, monotonically increasing relationship between quality of particular games and both software unit sales and the sale of hardware. Gretz (2010) suggests that, contrary to the literature on indirect network effects which tends to assume symmetric demand for all software titles, there is a wide variety in both the popularity and profitability of video games and that further analysis should focus in particular upon killer applications.

\section{3: Data}

The dataset used in this study represents a snapshot of the US video game market during September 2011. The dependent variable used in the empirical analysis is the lifetime unit sales of games released in the US after September 2010, which were collected from an online database maintained by VGChartz.com. Figure 2 shows a graphical representation of the dependent variable, where the heavily tailed nature of the distribution is obvious. This supports various claims from the literature that a minority of titles are responsible for a disproportionally high proportion of total sales, with the top ten per cent of titles observed to be responsible for over fifty-four per cent of total unit sales. Just under twenty-eight per cent of titles in the sample sold fewer than one-hundred thousand copies. The long-tailed nature of the variable can be demonstrated via a comparison of the mean and median value, where the median title sold one hundred and ninety thousand copies against a mean of four hundred and eighty thousand.

[Figure 2 about here] 
The long-tailed nature of the unit sales variable is more formally analysed using the STABLE software package written by John Nolan. Four parameters are reported on the heavy-tailed distribution in Table 1 (below), these being; $\alpha$, the tail index (where $0 \leq \alpha \leq 2$ ); $\beta$ the skewness parameter (where -1 $\leq \beta \leq 1$ ); $\gamma$, the scale parameter (where $\gamma \geq 0$ ) and $\delta$, the location parameter. As the estimated value of $\beta$ is exactly equal to 1 , this implies that the quantile estimators should be used in favour of the maximum likelihood estimators. Of these quantile estimations, only the ' $\mathrm{SO}$ ' parameterisations are reported, where these are based on the Zolotarev's (1983) M for an alpha stable distribution with skewness $=\beta$, as well as an intuitive interpretation relative to other parameters. All three outputs estimate the value of $\alpha$ to be 1.0573 , which implies that the variance of the unit sales variable is unbounded, but not the mean. This suggests that standard OLS regression output should be interpreted with caution and that either an appropriate transformation of the dependent variable should be carried out before OLS regression results are generated, or that alternative modelling procedures should be considered. This study adopts both of these approaches in order to check for consistency and robustness in the empirical estimations.

[Table 1 about here]

The regression analysis includes a number of variables that could theoretically explain variations in unit sales, these being largely consistent with control variables included in the analysis of blockbuster films undertaken by Collins et al. (2002), where critical response, genre, age-rating, and film characteristics are included as control variables. In this study the explanatory variables include a measure of the quality of the title as indicated by its metacritic score. This is a value ranging between zero and one-hundred and is based on a weighted measure of the critical response received in a wide selection of well-known news and media outlets. Additional variables include the age rating of the title, the maximum number of players allowed simultaneously at any one time, whether it is officially licensed and whether the game comes packaged with an accessory. Other control variables include the hardware platform of release, developer, genre, theme, perspective of play and whether or not the title is a sequel or rerelease. A vast majority of these variables are 
collected in binary form based on the information appearing in the video games database hosted on the website MobyGames, except the latter two variables which are the author's own observations. Full information on the variables appearing in the regression analysis can be found in Table 1. The final dataset consists of 1,770 video games titles released on the current generation of hardware platforms.

[Table 2 about here]

\section{4: Results}

An OLS regression analysis is performed, where the functional form of the modelis as follows:

$$
\begin{aligned}
& \ln \text { SALES }_{i}=\beta_{0}+\beta_{1} \text { YEAR }_{i}+\beta_{2} \text { SEQ }_{i}+\beta_{3} \text { REREL }_{i}+\beta_{4} \text { REV }_{i}+\beta_{5} \text { RATING }_{i}+\beta_{6} \text { PLAYER }_{i} \\
& +\beta_{7} \text { ONLINE }_{i}+\beta_{8} \text { LIC }_{i}+\beta_{9} \text { ACC }_{i}+\beta_{10} \text { MULTI }_{i}+\beta_{11} \text { PLAT }_{i}+\beta_{12} \text { GENRE }_{i}+\beta_{13} \text { VIEW }_{i}+\beta_{14} \text { DEV }_{i}+\mu
\end{aligned}
$$

The dependent variable is the logarithm of US unit sales in thousands. Most of the independent variables are defined in Table 1 and reflect the relevant observation for the $\mathrm{i}^{\text {th }}$ video game title. Each of RATING, PLAT, GENRE, VIEW, DEV arevectors of variables reflecting age-ratings, hardware platform, genre, viewpoint and developer respectively. The output from this regression can be found in Table 2.

[Table 2 about here]

In the general model specification, it appears that one of the most statistically significant variables is the review score. A one unit increase in the metacritic review score (in this case, each unit change effectively represents a one per cent change) is found to increase unit sales by approximately one and a half per cent. Thus, a ten per cent increase in the review score would typically increase unit sales by around fifteen per cent. The evidence from these regressions suggests that video game unit 
sales are quality elastic. Other key characteristics that are found to influence sales by a statistically significant amount include whether or not the title is a sequel to an existing franchise (increasing sales on average by around six per cent), the age rating of the game (games with a 'mature' rating are found to sell around ten per cent more than the control case of games with an 'everyone' rating) and whether the title appears on multiple platforms (multi-platform titles are found to sell around eight per cent more units than titles that are exclusive to a given platform). It should be noted that games of the same name released for different consoles are each considered unique titles for the purposes of this study, so this result does not simply reflect the broader availability of multiplatform titles. An interpretation of this finding could be that multi-platform titles are associated with a more coherent marketing effort and also afford greater opportunity to enjoy network externalities in allowing players to discuss and enjoy various aspects of a particular game with other gamers regardless of the specific hardware platform owned.

Year of release is associated with a lower quantity of unit sales, with each additional year between releases found to result in a reduction of around two per cent in the number of copies sold. As this represents a variable included to control for the passage of time in the dataset, the estimated value of the coefficient attached to this variable is entirely intuitive. Simply put, games that have been available for a longer period of time are likely to have sold more copies than relatively newer games. However, it is interesting to note that the passage of time is found to result in only a relatively small increase in sales, which indicates that a vast majority of activity takes place in the period immediately following release. The other control variables included to reflect the hardware platform are also found to have a significant influence on unit sales, with all measurements taken relative to the control case of the Xbox 360 . Titles for handheld platforms are found, on average, to sell significantly fewer copies than for home platforms, with games for the Sony PSP and the Nintendo DS selling on average thirty and thirteen per cent less than Xbox 360 games respectively. Among the home consoles, PS3 games were found to sell around seven per cent fewer copies than the base case, while Nintendo Wii games sold around five per cent more on average, with the latter 
estimate not found to be statistically different from zero. This clearly matches the pattern of sales trends presented in Figure 1, where the Xbox 360 and Nintendo Wii are seen to be the home consoles with the highest installed user-bases, the former particularly offering network externalities through the provision of its X-Box Live service. However, the reduced average sales levels observed for the NDS is somewhat puzzling given the number of hardware units sold, perhaps indicating that handheld console owners tend to buy relatively fewer games on average compared with home console owners.

Relative to the base case of the action genre, a number of specific game types are found to associate with significantly different average sales. Adventure, sport and strategy genres are found to reduce unit sales by about ten, ten and fifteen per cent respectively, whereas educational games are found to sell around thirty-seven per cent more copies on average compared with the base case. Additionally, some of the viewpoints taken by the player are also found to affect unit sales on average relative to the first-person. Platform and third-person perspectives are found to associate with sales increases of around eleven and five per cent respectively, while a top-down view is found on average to reduce unit sales by around eight per cent. Finally, the release of a game through a major publisher is found in many cases to affect unit sales. This could proxy for marketing effort or the subjective element of utility derivation, with output from different publishers often having a unique look, feel and playing style that is otherwise difficult to quantify. Many major publishers associate on average with higher sales than the base case, namely (with the statistically significant percentage increase stated in parenthesis); Activision (twenty-four per cent), Capcom (fourteen per cent), Disney (thirty-two per cent), EA (twenty-six per cent), Microsoft (thirty-five per cent), Nintendo (sixty-three per cent), Rockstar (forty-two per cent), Sony (thirty-two per cent), Sega (fourteen per cent) and THQ (eighteen per cent). The only significant reduction in unit sales observed for a major publisher is Eidos, with sales on average being around thirteen per cent less than non-major publishers. Major publishers, particularly Nintendo, are therefore found to be associated with significant differences in the unit sales of video games titles. It should also be noted 
that three of the largest estimated influences on unit sales relate to the three hardware manufacturers Nintendo, Microsoft and Sony. To an extent, this reinforces the findings of Evans et al. (2005) that suggests killer-apps are almost always produced by hardware manufacturers themselves.

Table 2 also contains a preferred model specification which excludes any variables not found to be significant at the ninety-five per cent confidence interval or above. The estimated parameters are largely consistent with those appearing in the general specification, with the same signs and relative orders of magnitude observed for all remaining model variables. The largest variations from the original specification are observed for the platform-dummy variables (showing an eighteen and thirty-three per cent reduction in sales relative to the base case of the Xbox 360 for NDS and PSP titles respectively, rather than the thirteen and twenty-nine per cent respectively estimated in the original regression). Otherwise the parameter estimates common to both models seem to be largely consistent.

However, even allowing for the logarithmic transformation applied in the above regressions, OLS regressions are likely to produce biased results due to the long-tailed nature of the dependent variable. Thus, to check for robustness, a series of binary logistic regressions are specified in Table 3 where the dependent variable reflects whether or not the particular observation represents a blockbuster title. The independent variables in these regressions are identical to those outlined in Equation (1) and detailed in Table 1. The model output from logistic regressions is specified as follows:

$$
\operatorname{Pr}\left(S_{i}>T\right)=\frac{e^{\beta^{\prime} x_{i}}}{1+e^{\beta^{\prime} x_{i}}}
$$

In other words, the model predicts the probability that sales of the $\mathrm{i}^{\text {th }}$ title $\left(\mathrm{S}_{\mathrm{i}}\right)$ will exceed a nominated threshold $(T)$. Of course, the sales threshold that distinguishes a blockbusterfrom other 
titles is entirely subjective. To minimise the impact of this subjectivity on the results, a range of alternative unit sale thresholds are considered across three separate binary logistic regressions. The thresholds are set at US sales of two million units, one million units and five-hundred thousand units. These thresholds accord with a proportion of the overall sample of around one per cent, four per cent and eleven per cent respectively. In common with the OLS output, the metacritic review score is found to have a highly significant association with unit sales at above the ninety-nine per cent confidence interval. This provides stronger evidence that better quality games are more likely to become blockbusters. However, the influence of this variable at the margin is found to increase as the unit sales threshold employed becomes higher, with the probability of achieving blockbuster status expected to increase by between twenty-two per cent and nine per cent for every one unit increase in the review score, depending upon the chosen threshold. This finding indicates that high quality becomes more important in determining success among the very top blockbusters. Games rated for a teen audience are found to be less likely to become blockbusters at higher thresholds. This indicates an inverted ' $u$ ' shaped relationship between age rating and likelihood of success, whereby games targeted at a general or mature audiences are both found to be more likely to become blockbusters at higher thresholds than those aimed at a teen audience. Higher numbers of players allowed by the game at any one time are associated with a higher probability of success, with the associated coefficient found to be statistically significant at the ninety-five per cent confidence interval when the threshold is set at either one or two million units sold, but not when the threshold is set to half a million units.

In each of these logistic regressions, the platform of release is found to have a significant influence on the likelihood of a video game title becoming a blockbuster. However, in contrast to the findings from the OLS regressions, the only platforms that are found to have a statistically significant (negative) influence are the Sony PS3 and PSP consoles, with the latter associated with a much higher reduction than the former. In common with the OLS regression output, educational titles are found to have a significantly higher probability of achieving blockbuster status at all three indicative 
thresholds relative to the action genre, whereas sports and strategy titles significantly lower. For educational titles, the increased likelihood of success is relatively consistent across the three blockbuster thresholds. In the case of sports and strategy genres, the there is a clear reduction in the reduced probability of success at the lowest sales threshold compared to the two highest. There are also several statistically significant coefficients attached to each of the player viewpoint variables relative to the first-person, although there doesn't seem to be a particularly consistent pattern across different thresholds or particular viewpoints. Side-scrolling perspectives are always found to associate with a reduced probability of blockbuster status, but only significantly so where the threshold is set at either one or two million copies sold. Platform and third-person viewpoint titles are found to have an increased probability of success relative to the base case, but only significantly so where the threshold is set at half a million units sold. Particular publishers are also found to be associated with significantly different probabilities of success, with consistent results found for Activision, Nintendo, Rockstar and Sony, which are all found to be associated with statistically significantly higher probabilities of releasing games that achieve blockbuster status across all three thresholds. Generally, major publishers are found to have a strong, positive influence on the probability of success, with any negative parameters generally being either inconsistent across thresholds or lacking statistical significance. The only significant negative coefficient estimated across the three specifications is for Konami when the threshold is lowered to half a million units sold.

[Table 3 about here]

In summary, after modelling the data in a number of different ways, certain characteristics are consistently found to associate with an increased likelihood of a video game achieving blockbuster status. These are the metacritic review score, which proxies for the quality of the game, the platform for which the title is released, which proxies for the size of the installed user base and the publisher of the title, which potentially proxies for both marketing effort and subjective elements of 
gameplay that affect the utility derived by the player. Therefore a game that has the best chance of becoming a blockbuster would need to be released on popular platforms by a major publisher, while also offering a high-quality gameplay experience.

\section{5: Conclusion}

This study investigates the factors that affect the likelihood of a video game becoming a blockbuster. A unique dataset is collected consisting of approximately 1,800 observations relating to individual video games titles released across a variety of platforms. The dataset incorporates information on the quality of gameplay experience from Metacritic, gameplay characteristics from the video games database maintained by MobyGames and lifetime US unit sales from VGChartz. Due to the longtailed nature of the dependent variable, OLS regressions of the logarithm of unit sales are estimated alongside binary logistic regressions based on three different thresholds of sales success. The results indicate that three factors are consistently and significantly associated with an increased probability of a given title achieving a high volume of sales. Blockbuster games are more likely to be released by major publishers, particularly Activision, Nintendo, Rockstar or Sony and are also more likely to be released on popular home platforms. Finally, successful video games are found in every model specification to be, on average, better quality titles than less successful titles. As quality is proxied by critical response, this paper offers evidence to suggest that the purchasing decisions of consumers are strongly influenced by review scores.

The significant managerial implications of these findings are twofold. First, for a developer or publisher to maximise the chances of securing a blockbuster release, the selection of appropriate hardware platform is found to be vitally important. Blockbuster titles tend to be released on home platforms with higher installed user bases that allow for increased exploitation of network externalities via online interactions. During the time period under analysis, it would appear that the Xbox 360 is the hardware platform that best fits this description, as Xbox Live typically offers a better quality online experience than that of the Nintendo Wii, while the PS3 lacks the installed user base. 
Second, as quality is found to be one of the most important factors affecting the likelihood of a video game becoming a blockbuster, optimisation of the gameplay experience would seem to have considerably more impact on sales than, say, paying for a license or franchise endorsement. This may challenge conventional wisdom relating to the most effective use of available resources in the development of a potential blockbuster.

\section{6: References}

Activision Press Release. (2011a). Call of Duty: Modern Warfare 3 sets new five-day entertainment record grossing more than $\$ 775$ million worldwide, accessed $17^{\text {th }}$ November 2011 from: http://investor.activision.com/releasedetail.cfm?ReleaselD=624766

Activision Press Release. (2011b). Call of Duty: Modern Warfare 3 hits $\$ 1$ billion milestone in just 16 days, accessed $12^{\text {th }}$ December 2011 from:

http://investor.activision.com/releasedetail.cfm?ReleaselD=632389

Aoyama, Y. \& Izushi, H. (2003).Hardware gimmick or cultural innovation?Technological, cultural and social foundations of the Japanese video games industry. Research Policy, 32, $423-444$.

Binken, J.L.G. \& Stremersch, S. (2009). The effect of superstar software on hardware sales in system markets. Journal of Marketing, 73 (2), 88 - 104.

Clements, M.T. \& Ohashi, H. (2004). Indirect network effects and the product cycle: Video games in the US, 1994-2002. NET Institute Working Paper, No. 04-01.

Collins, A., Hand, C. \& Snell, M. C. (2002). What makes a blockbuster? Economic analysis of film success in the United Kingdom. Managerial and Decision Economics, 23, 343-354.

Coughlan, P. (2001). Note on the home video game technology and industry structure. Harvard Business School Case, 9-700-107. 
Cringely, R. X. (1996). Accidental empires. Harper Business, New York, USA.

De Vany, A. \& Walls, W.D. (1999). Uncertainty in the movie industry: Does star power reduce the terror of the box office? Journal of Cultural Economics, 23, 285-318.

Eurogamer. (2011). Call of Duty: Modern Warfare 3 biggest entertainment launch ever, accessed $11^{\text {th }}$ November 2011 from:http://www.eurogamer.net/articles/2011-11-11-call-of-duty-modern-warfare3-biggest-entertainment-launch-ever

Evans, D.S., Hagiu, A. \& Schmalensee, R. (2005). A survey of the economic role of software platforms in computer based industries. CESifo Economic Studies, 51 (2-3), $189-224$.

Gallagher, S. \& Park, S.O. (2002). Innovation and competition in standard-based industries: A historical analysis of the U.S. home video game market. IEEE Transactions on Engineering Management, 49 (1), $67-82$.

Gamrreview. (2011). Accessed $29^{\text {th }}$ September 2011 via http://gamrreview.vgchartz.com/.

Gretz, R.T. (2010). Console price and software availability in the home video game industry. Atlantic Economic Journal, 38, $81-94$.

Neuman, W. (1991). The future of the mass audience, Cambridge University Press, Cambridge, UK.

Prag, J. \& Casavant, J. (1994). An empirical study of the determinants of revenues and marketing expenditures in the motion picture industry. Journal of Cultural Economics, 18, 217-227.

Shankar, V. \& Bayus, B.L. (2003). Network effects and competition: An empirical analysis of the home video games industry. Strategic Management Journal, 24 (4), 375 - 384.

Shintaku, J. \& Ikuine, F. (1999). Katei-yogemusofutoniokerukaihatsusenryaku no hikaku: kaihatsushakakaekomisenryaku to gaibuseisakushakatsuyosenryaku. ITME Discussion Paper No. 22, March, University of Tokyo, Tokyo. 
Smith, S.P. \& Smith, V.K. (1986). Successful movies: A preliminary empirical analysis. Applied Economics, 18, $501-507$.

Sochay, S. (1994). Predicting the performance of motion pictures. Journal of Media Economics, 7, 1 20.

The Economist. (2011). All the world's a game. Accessed $17^{\text {th }}$ December 2011 from: http://www.economist.com/node/21541164

VGChartz.(2011). Hardware annual summary. Accessed $28^{\text {th }}$ November 2011 from:

http://www.vgchartz.com/hw annual summary.php.

Wallace, W., Seigerman, A. \& Holbrook, M. (1993). The role of actors and actresses in the success of films: How much is a movie star worth? Journal of Cultural Economics, 17, 1- 27.

Williams, D. (2002). Structure and competition in the U.S. home video game industry. The International Journal on Media Management, 4 (1), 1424 - 1277.

Zolotarev, V.M. (1983). Probability metrics. Teor. Veroyatnost. iPrimenen, 28, 278-302. 
Tables\& Figures
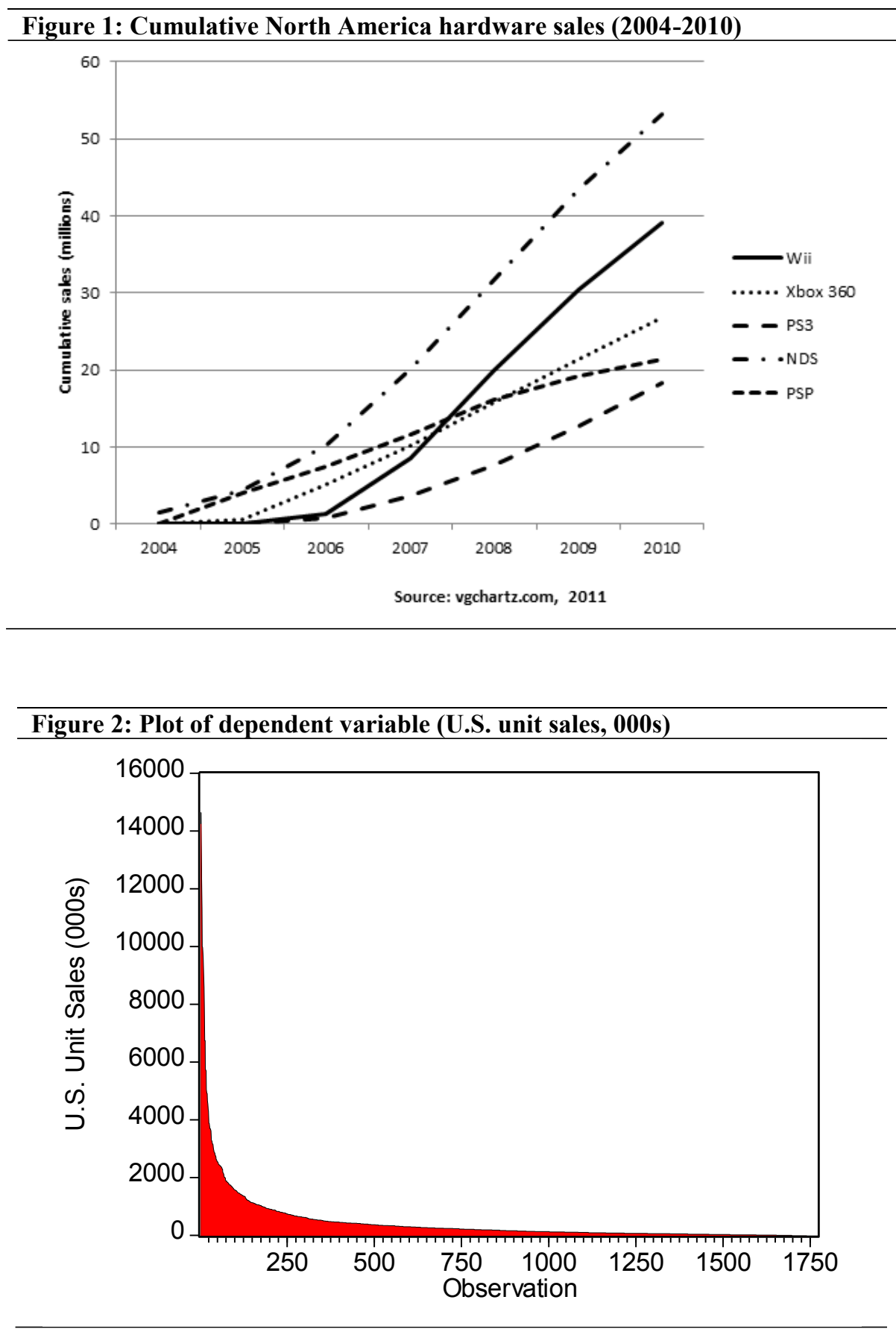


\begin{tabular}{llll}
\hline \multicolumn{4}{l}{ Table 1: STABLE estimates of parameters } \\
\hline $\boldsymbol{\alpha}$ & $\boldsymbol{\beta}$ & $\boldsymbol{\gamma}$ & $\boldsymbol{\delta}$ \\
\hline 1.0573 & 1.0000 & 180.000 & 190.000 \\
\hline
\end{tabular}






\begin{tabular}{|c|c|c|c|c|}
\hline & \multicolumn{2}{|c|}{ General Model } & \multicolumn{2}{|c|}{ Preferred Model } \\
\hline & Coefficient & t-value & Coefficient & t-value \\
\hline CONSTANT & 47.719 & 2.958 & 55.456 & 3.604 \\
\hline YEAR & -0.023 & -2.888 & -0.027 & -3.526 \\
\hline SEQ & 0.060 & 2.847 & 0.062 & 3.021 \\
\hline REREL & 0.013 & 0.290 & - & \\
\hline REV & 0.014 & 16.56 & 0.015 & 17.719 \\
\hline RATET & 0.017 & 0.691 & - & - \\
\hline RATEM & 0.109 & 3.324 & 0.105 & 3.794 \\
\hline PLAYER & 0.010 & 1.068 & - & - \\
\hline ONLINE & 0.027 & 1.125 & - & - \\
\hline LIC & 0.004 & 0.154 & - & - \\
\hline ACC & -0.028 & -0.280 & - & - \\
\hline MULTI & 0.076 & 3.282 & 0.082 & 3.660 \\
\hline NDS & -0.132 & -3.674 & -0.188 & -6.006 \\
\hline WII & 0.047 & 1.471 & - & - \\
\hline PS3 & -0.067 & -2.563 & -0.076 & -3.123 \\
\hline PSP & -0.293 & -8.267 & -0.335 & -10.170 \\
\hline $\mathrm{ADV}$ & -0.096 & -2.621 & -0.104 & -2.886 \\
\hline EDU & 0.370 & 2.432 & 0.376 & 2.506 \\
\hline RAC & -0.013 & -0.351 & - & - \\
\hline RPG & 0.019 & 0.570 & - & - \\
\hline SIM & -0.008 & -0.213 & - & - \\
\hline SPT & -0.101 & -3.319 & -0.090 & -3.303 \\
\hline STR & -0.148 & -4.522 & -0.147 & -4.576 \\
\hline PLA & 0.110 & 2.685 & 0.072 & 1.970 \\
\hline ISO & -0.023 & -0.512 & - & - \\
\hline SID & -0.080 & -1.948 & - & - \\
\hline TOP & -0.080 & -2.360 & -0.079 & -2.347 \\
\hline $3^{\mathrm{RD}}$ & 0.053 & 2.058 & 0.053 & 2.163 \\
\hline $2 \mathrm{KG}$ & 0.080 & 1.623 & - & - \\
\hline $\mathrm{ACT}$ & 0.242 & 5.887 & 0.228 & 6.216 \\
\hline ATA & -0.036 & -0.555 & - & - \\
\hline CAP & 0.141 & 2.660 & 0.127 & 2.556 \\
\hline DIS & 0.323 & 2.645 & 0.324 & 2.699 \\
\hline EID & -0.130 & -1.902 & -0.153 & -2.338 \\
\hline EAG & 0.258 & 7.548 & 0.237 & 8.303 \\
\hline KON & -0.083 & -1.601 & - & - \\
\hline MIC & 0.346 & 4.505 & 0.323 & 4.403 \\
\hline MID & 0.143 & 1.642 & - & - \\
\hline NAM & -0.015 & -0.259 & - & - \\
\hline NIN & 0.633 & 9.763 & 0.632 & 10.121 \\
\hline ROC & 0.416 & 3.933 & 0.396 & 3.943 \\
\hline SON & 0.317 & 6.786 & 0.306 & 7.012 \\
\hline SEG & 0.143 & 2.918 & 0.120 & 2.608 \\
\hline THQ & 0.180 & 4.016 & 0.158 & 3.934 \\
\hline SQE & 0.051 & 0.787 & - & - \\
\hline UBI & 0.076 & 1.863 & - & - \\
\hline $\mathrm{N}$ & & & & \\
\hline $\mathrm{R}^{2}$ & & & & \\
\hline $\mathrm{F}$ & & 30.99 & & 3.012 \\
\hline Normality & & & & \\
\hline
\end{tabular}




\begin{tabular}{|c|c|c|c|c|c|c|c|c|c|}
\hline & \multicolumn{3}{|c|}{$T=2 m$} & \multicolumn{3}{|c|}{$T=1 m$} & \multicolumn{3}{|c|}{$T=0.5 m$} \\
\hline & Coefficient & & Std Error & Coefficient & & Std Error & Coefficient & & Std Error \\
\hline CONSTANT & 303.314 & & 268.707 & 231.7 & & 158.071 & 42.31 & & 118.362 \\
\hline YEAR & -0.161 & & 0.134 & -0.121 & & 0.079 & -0.025 & & 0.059 \\
\hline SEQ & 0.259 & & 0.392 & 0.043 & & 0.207 & 0.147 & & 0.150 \\
\hline REREL & -0.806 & & 0.827 & -0.897 & & 0.504 & 0.186 & & 0.315 \\
\hline REV & 0.201 & $* * *$ & 0.029 & 0.119 & $* * *$ & 0.012 & 0.090 & $* * *$ & 0.008 \\
\hline RATET & -2.470 & ${ }^{* * *}$ & 0.634 & -0.603 & $* * *$ & 0.285 & 0.051 & & 0.190 \\
\hline RATEM & -0.653 & & 0.621 & 0.168 & & 0.326 & 0.296 & & 0.244 \\
\hline PLAYER & 0.30 & ** & 0.134 & 0.076 & ${ }^{* *}$ & 0.080 & 0.075 & & 0.059 \\
\hline ONLINE & -0.116 & & 0.429 & 0.268 & & 0.242 & 0.140 & & 0.174 \\
\hline LIC & -0.233 & & 0.534 & 0.017 & & 0.261 & -0.188 & & 0.179 \\
\hline MULTI & 0.619 & & 0.556 & 0.309 & & 0.273 & 0.186 & & 0.184 \\
\hline NDS & -0.938 & & 0.795 & -0.149 & & 0.414 & -0.084 & & 0.285 \\
\hline WII & -0.265 & & 0.594 & 0.213 & & 0.336 & 0.183 & & 0.245 \\
\hline PS3 & -1.600 & $* * *$ & 0.591 & -0.782 & $* *$ & 0.294 & -0.449 & $* *$ & 0.209 \\
\hline PSP & -2.120 & $* *$ & 1.001 & -2.106 & $* *$ & 0.505 & -0.918 & $* * *$ & 0.278 \\
\hline $\mathrm{ADV}$ & 0.016 & & 0.810 & -1.417 & & 0.547 & -0.355 & & 0.315 \\
\hline EDU & 2.766 & ${ }^{* *}$ & 1.152 & 2.280 & ${ }^{* *}$ & 0.849 & 2.154 & $* * *$ & 0.748 \\
\hline RAC & -0.462 & & 0.569 & -0.057 & & 0.308 & 0.220 & & 0.221 \\
\hline RPG & 0.352 & & 0.530 & 0.086 & & 0.319 & -0.178 & & 0.241 \\
\hline SIM & 0.221 & & 0.560 & -0.372 & & 0.328 & -0.329 & & 0.239 \\
\hline SPT & -1.323 & $* *$ & 0.651 & -1.254 & $* *$ & 0.345 & -0.553 & $* *$ & 0.222 \\
\hline STR & -2.940 & $* * *$ & 1.028 & -2.071 & $* * *$ & 0.511 & -1.252 & $* * *$ & 0.291 \\
\hline PLA & 0.755 & & 0.652 & 0.316 & & 0.389 & 0.732 & $* * *$ & 0.280 \\
\hline SID & -1.831 & $* *$ & 0.846 & -0.695 & $* *$ & 0.483 & -0.534 & & 0.330 \\
\hline TOP & -0.804 & & 0.814 & -0.527 & & 0.434 & -0.077 & & 0.266 \\
\hline $3^{\mathrm{RD}}$ & 0.376 & & 0.436 & 0.547 & & 0.262 & $0.364^{*}$ & * & 0.189 \\
\hline $2 \mathrm{KG}$ & -1.162 & & 1.265 & -0.329 & & 0.601 & 0.652 & $* * *$ & 0.382 \\
\hline $\mathrm{ACT}$ & 2.179 & $* * *$ & 0.620 & 0.693 & ${ }^{* * *}$ & 0.344 & 0.809 & $* * *$ & 0.260 \\
\hline CAP & -0.396 & & 1.135 & 0.291 & & 0.510 & -0.185 & & 0.422 \\
\hline EAG & -0.323 & & 0.835 & -0.093 & & 0.361 & 1.046 & $* * *$ & 0.224 \\
\hline KON & 0.122 & & 1.278 & -0.164 & & 0.699 & -1.284 & $* *$ & 0.648 \\
\hline MIC & 1.851 & $* *$ & 0.868 & 0.921 & ${ }^{* *}$ & 0.597 & 0.672 & & 0.493 \\
\hline NIN & 3.166 & $* * *$ & 0.724 & 1.999 & $* * *$ & 0.371 & 2.038 & $* * *$ & 0.299 \\
\hline ROC & 1.938 & * & 1.027 & 1.893 & $*$ & 0.697 & 1.446 & ** & 0.616 \\
\hline SON & 1.588 & $*$ & 0.937 & 1.431 & $*$ & 0.469 & 0.952 & $* * *$ & 0.324 \\
\hline SEG & 0.030 & & 1.142 & 0.156 & & 0.474 & 0.244 & & 0.319 \\
\hline UBI & 0.459 & & 0.828 & -0.218 & & 0.443 & 0.309 & & 0.299 \\
\hline $\mathrm{N}$ & 71 & & & 185 & & & 382 & & \\
\hline Log-Liklihood & -141.262 & & & -379.516 & & & -666.335 & & \\
\hline Chi-Squared $(36)=$ & 312.98 & $* * *$ & & 425.03 & $* * *$ & & 510.29 & $* * *$ & \\
\hline
\end{tabular}

